\title{
Systematic review of the effect of robot-aided therapy on recovery of the hemiparetic arm after stroke
}

\author{
Gerdienke B. Prange, MSc; ${ }^{*}$ Michiel J. A. Jannink, PhD; ${ }^{1}$ Catharina G. M. Groothuis-Oudshoorn, PhD; ${ }^{1}$ \\ Hermie J. Hermens, PhD; ${ }^{1-2}$ Maarten J. IJzerman, PhD, PT ${ }^{1,3}$ \\ ${ }^{1}$ Roessingh Research and Development, Enschede, the Netherlands; ${ }^{2}$ Department of Biosignals and Systems, \\ University of Twente, Enschede, the Netherlands; ${ }^{3}$ Biomedical Technological Institute, University of Twente, \\ Enschede, the Netherlands
}

\begin{abstract}
A limited number of clinical studies have examined the effect of poststroke rehabilitation with robotic devices on hemiparetic arm function. We systematically reviewed the literature to assess the effect of robot-aided therapy on stroke patients' upper-limb motor control and functional abilities. Eight clinical trials were identified and reviewed. For four of these studies, we also pooled short-term mean changes in FuglMeyer scores before and after robot-aided therapy. We found that robot-aided therapy of the proximal upper limb improves short- and long-term motor control of the paretic shoulder and elbow in subacute and chronic patients; however, we found no consistent influence on functional abilities. In addition, robotaided therapy appears to improve motor control more than conventional therapy.
\end{abstract}

Key words: cerebrovascular accident, exercise therapy, motor recovery, proximal upper limb, rehabilitation, robot-aided therapy, robotics, stroke, systematic review, upper limb.

\section{INTRODUCTION}

A cerebrovascular accident (CVA), or stroke, is a sudden ischemic or hemorrhagic disturbance in the blood supply to brain tissue that results in partial loss of brain function. The incidence of stroke in the Netherlands is 162 per 100,000 people, which means approximately 25,000 new patients each year [1]. In the United States, approximately 500,000 people $(171$ per 100,000$)$ experience a stroke each year [2]. This high stroke incidence, in combination with an aging population, which implies future increases in incidence, greatly strains national healthcare services and related costs.

A stroke causes partial destruction of cortical tissue and results in disturbed generation and integration of neural commands. The interrupted generation and integration of neural commands from the sensorimotor areas of the cortex results in a reduced or even absent ability to selectively activate muscle tissue, which affects motortask performance. A consequence of disturbed neural command generation in the sensorimotor cortex is impaired arm and hand motor function [3]. Optimal restoration of arm and hand motor function is essential for stroke patients to independently perform activities of daily living (ADL).

Abbreviations: $\mathrm{ADL}=$ activities of daily living, $\mathrm{ARM}=$ Assisted Rehabilitation and Measurement (guide), $\mathrm{CI}=$ confidence interval, CIRRIE = Center for International Rehabilitation Research Information and Exchange, CVA = cerebrovascular accident, FIM = Functional Independence Measure, FM = FuglMeyer, MIME $=$ Mirror Image Motion Enabler, MIT = Massachusetts Institute of Technology, RCT $=$ randomized controlled trial, $\mathrm{SD}=$ standard deviation.

* Address all correspondence to Gerdienke B. Prange, MSc; Roessingh Research and Development, PO Box 310, 7500 AH Enschede, the Netherlands; +31 53 4875759; fax: +31 53 4340849. Email: G.Prange@rrd.nl

DOI: 10.1682/JRRD.2005.04.0076 
High-intensity and task-specific upper-limb treatment consisting of active, highly repetitive movements is one of the most effective approaches to arm- and handfunction restoration [4-6]. Unfortunately, standard multidisciplinary stroke rehabilitation is labor-intensive and requires one-to-one manual interactions with therapists. Treatment protocols entail daily therapy for several weeks, which makes the provision of highly intensive treatment for all patients difficult [7]. In addition, the evaluation of patients' performance and progress is usually subjective because few adequate objective measures are available [7-8].

Given these problems in stroke rehabilitation, researchers saw an opportunity to create new, technological solutions. The use of robotic devices in rehabilitation can provide high-intensity, repetitive, task-specific, and interactive treatment of the impaired upper limb and an objective, reliable means of monitoring patient progress. With robotic devices, patients may achieve increased gains from rehabilitation treatment.

Many research groups have developed robotic devices for upper-limb rehabilitation, for example, Massachusetts Institute of Technology (MIT)-Manus [9], Assisted Rehabilitation and Measurement (ARM) Guide [10], Mirror Image Motion Enabler (MIME) [11], BiManu-Track [12], GENTLE/S [13], Neurorehabilitation Robot (NeReBot) [14], REHAROB [15], Arm Coordination Training 3-D $\left(\mathrm{ACT}^{3 \mathrm{D}}\right)$ [16], and ARMin [17]. The training these devices provide is based on exercise therapy modalities that the literature and/or clinical practice indicate may help restore upper-limb motor control and function. One such modality is passive movement, in which the robotic device moves the patient's arm (possible in all robotic devices). Another modality is active movement that is either partially assisted by the robotic device, in the case of some voluntary but inadequate function (possible with all robotic devices), or resisted by the robotic device, in the case of voluntary and selective function (only evaluated in MIT-Manus, Bi-Manu-Track, MIME) [9,11-12]. A further modality is bimanual exercise, in which active movement of the unaffected arm is mirrored by simultaneous passive movement of the affected arm by the robotic device (only possible in BiManu-Track and MIME) [11-12]. In most robotic systems, more than one modality is incorporated into a single robotic device. Most robotic devices were designed for training the proximal upper limb (shoulder and elbow) of the hemiparetic arm by enabling movement in multiple directions [9-11,13-14,16,18-19]. The BiManu-Track focuses on the distal upper limb (forearm and wrist) [12], as does a recent extension of the MITManus robotic device for training of wrist movements [20]. New robotic devices and evolutions of existing devices are continuously being designed (e.g., Furusho et al. [21] and Colombo et al. [22]) and include several systems for training hand movements (e.g., the force feedback glove of Merians et al. [23] and the devices of Kline et al. [24] and Mulas et al. [25]).

The design and development of robotic devices have been reported extensively, but only a few clinical studies, which varied in design and methods, have examined the effect of robotic devices on stroke rehabilitation in a clinical setting.

Insight into the use of robot-aided therapy can be obtained through systematic analysis of the literature. Our main objective in performing this systematic analysis was to investigate the effect of robot-aided therapy on the upper-limb motor control and functional abilities of stroke patients.

\section{METHODS}

\section{Literature Search}

We conducted a systematic search of articles from 1975 to August 2005 in the PubMed, Cochrane Controlled Trials (Rehabilitation and Related Therapies), Center for International Rehabilitation Research Information and Exchange (CIRRIE, http://cirrie.buffalo.edu/), and National Rehabilitation Information Center for Independence REHABDATA (http://www.naric.com) databases. CIRRIE includes research from all areas of rehabilitation conducted outside the United States from 1990 to 2005. We consulted REHABDATA for rehabilitation research conducted within the United States.

We used the following key words in these searches: arm, arms, cerebrovascular accident, CVA, hemiplegia, hemipleg*, hemiparesis, hemipare*, robotics, robot*, stroke, upper extremities, upper extremity, upper limb, and upper limbs. The search strategy that we used for PubMed is presented in the Appendix (available online only at http://www.rehab.research.va.gov/). This strategy was adjusted to suit the other databases. In addition to searching the databases, we checked the references of relevant publications and scanned the proceedings of the 2005 Institute of Electrical and Electronics Engineers 9th International Conference on Rehabilitation Robotics 
(Chicago, Illinois) for the most up-to-date developments in rehabilitation robotics.

\section{Study Selection}

Two reviewers independently selected and summarized studies and scored their methodological quality. The reviewers met regularly to discuss their findings and decisions. In the case of disagreement, a third reviewer was consulted.

To be selected for review, a study had to-

1. Be a clinical trial (i.e., compare pre- and posttreatment performance) or controlled trial (i.e., clinical trial with a control group, either randomized or not).

2. Involve stroke patients.

3. Concern movement therapy with a robotic device.

4. Focus on upper-limb motor control (and possibly functional abilities).

5. Use relevant motor control and functional ability outcome measures.

6. Be a full-length publication in a peer-reviewed journal.

Studies on the application of robotic devices for purposes other than therapeutic treatment (e.g., studies on ADL support aids) were excluded. To enable the most complete view of the current literature, we did not limit the search by patient subgroups (i.e., acute, subacute, or chronic) or by language.

In this review, we use "motor control" to indicate aspects of impairments in body functions and upper-limb structures (e.g., decreased strength) and "functional abilities" to indicate limitations in activities (e.g., inability to reach an object).

\section{Methodological Quality Judgment}

We selected studies with a variety of designs rather than only randomized controlled trials (RCTs), although RCTs provide the most reliable data on intervention effectiveness. We decided this because this research area is relatively young and only a few clinical studies on upperlimb robot-aided therapy after stroke have been published. The standard items for scoring the methodological quality of RCTs are not suitable for other study designs. Therefore, to evaluate the methodological quality of the selected studies, we applied Kottink et al.'s [26] adapted list of methodological items based on the Maastricht-Amsterdam criteria for RCTs [27]. This list contains 16 items on patient selection, intervention, outcome measurement, and statistics, each of which was scored as positive (yes), negative (no), or unclear (don't know). Each positive score received 1 point and each negative or unclear score received 0 points, with the exception of the study design item, which varied from 1 point for uncontrolled studies to 3 points for RCTs (RCT designs are less sensitive to bias). Thus, the maximum methodological quality score was 19 .

\section{Data Extraction}

We analyzed the contents of the selected studies using a structured diagram. By filling in this diagram, we were able to scan the general contents of the studies for-

1. Descriptive features of the subjects.

2. Intervention(s) implemented in the study.

3. Outcome measures for evaluation of the effects on both motor control and functional abilities.

4. Conclusions based on the results.

The extracted conclusions were considered positive if the change between pre- and posttreatment measurements or the difference between robot-trained and control groups was significantly different $(\alpha<0.05)$ as calculated by a statistical test appropriate to the research question and the data characteristics.

\section{Data Analysis}

In addition to the qualitative interpretation of studies, we performed a quantitative analysis for more objective insight into the effect of robot-aided therapy on motorcontrol recovery. The primary outcome measure for quantification of motor recovery was the upper-limb portion of the Fugl-Meyer (FM) assessment. Using a datapooling model appropriate to the characteristics and data of the selected studies, we pooled short-term changes in FM score before and immediately after robot-aided therapy into a mean difference across studies and calculated the 95 percent confidence interval (CI) of this pooled FM difference.

\section{RESULTS}

\section{Study Selection}

From the systematic literature search, we identified 17 clinical trials. Of these, 11 were clinical studies from the group that implemented the MIT-Manus beginning in 1997. These publications included several consecutive clinical trials and summaries of those clinical trials and often used the same subjects [9,28-33]. Of these 11 studies, only the most representative summary of the clinical trials was included in our analysis [32] along with four 
separate articles that were clearly dissimilar in research question or experimental setup from the studies in the summary [34-37]. Three studies that used the MIME also met the selection criteria. The second and third MIME studies [38-39] used the same subjects as the first MIME study [11], so we excluded the first study. Although the second and third studies used the same subjects, we included both because they focused on two separate aspects of robot-aided therapy (biomechanics [38] and muscle activation patterns [39]).

All selected studies concentrated on the restoration of proximal upper-limb function by training of the shoulder and elbow, except for two studies that tested a robotic device (Bi-Manu-Track) for training of the forearm and wrist $[12,40]$. Since distal upper-limb training is a different application than proximal upper-limb training, synthesis of the research would have been problematic. Therefore, these two Bi-Manu-Track studies were excluded. This reduced the number of selected studies to the eight studies summarized in Table 1 [10,32,34-39].

During data extraction, the two raters disagreed on 6 of the 80 general content items (8\%). These disagreements were resolved through discussion and the third reviewer was not consulted.

\section{Methodological Quality Judgment}

Two of the selected studies were experimental trials with pre- and posttreatment measurements of both an experimental and control group [32,38], of which one was an RCT [38]. The remaining six studies had a pre- and posttreatment measurement design for robot-aided therapy without a control group [10,34-37,39].

The wide range of study designs included in our review was reflected in the methodological quality scores that ranged from 8 [10] to 16 [36,38] out of a possible 19 points. The two raters disagreed on 7 of the 128 methodological quality items (5\%). Again, these disagreements were resolved through discussion and the third reviewer was not consulted.

\section{Patients}

The size of the experimental groups ranged from 3 [10] to 42 [35] (total $n=178$ ) and the sizes of the two control groups were 14 [38] and 36 [32] (total $n=50$ ). Except for the studies with 3 [10] and 9 [37] patients in the experimental group, all other studies involved at least 13 patients. Krebs et al.'s summary of multiple trials involved patients with subacute stroke (defined as 2 to
4 weeks poststroke, $n=40$ in the experimental groups and $n=36$ in the control groups) [32]. The remaining seven studies involved chronic stroke patients (defined as $>6$ mo poststroke, $n=138$ in the experimental groups and $n=14$ in the control groups) [10,34-39].

\section{Intervention}

Three different robotic devices were used for intervention across the eight studies: the MIT-Manus system was used in five studies [32,34-37], the MIME in two studies [38-39], and the ARM Guide in one study [10]. Technical details of these systems can be found elsewhere [10-11,32]. All eight studies included short-term pre- and posttreatment measurements, but only four studies included long-term assessments (varying from 3 mo to $3 \mathrm{yr}$ posttreatment) of the influence of robot-aided therapy [32,34-35,38].

The intervention in each study was robot-aided therapy. The training sessions were similar in seven studies and consisted of repetitive, goal-directed forward-reaching movements (i.e., the upper limb had to be stretched forward to reach the goal and the movement was not necessarily confined to two dimensions). The movements were actively performed by the subject (possibly partially assisted by the robotic device) [10,32,34-36,38-39]. One exception was the pilot evaluation of training of vertical (upward) movements that were assisted by MIT-Manus [37]. In Krebs et al.'s summary study [32], robot-aided therapy supplemented the conventional rehabilitation program. The other studies only used robot-aided therapy.

Participants in control groups received conventional therapy with additional noncontact or nonoperational exposure to the robot (i.e., the robot was turned off). The nature of the conventional therapy was not stated explicitly in those studies [32,38].

\section{Outcome Measures}

A total of 12 separate outcome measures were used across all studies: 10 motor control measures and 2 functional ability measures. Each study measured at least four different outcomes. All eight studies assessed motor control and six used the upper-limb portion of the FM [32,3438]. Only two studies measured functional abilities; both used the Functional Independence Measure (FIM) [34,38].

\section{Content of Studies}

Seven studies reported short-term improvements in motor control as a result of forward-directed robot-aided 
therapy (Table 1). The one study that investigated vertical movements did not report a significant improvement in motor control, although the trend was positive [37]. All four studies that assessed the long-term effects of robotaided therapy on motor control reported significant improvements [32,34-35,38]. Of the two studies that measured functional abilities, one found significant shortterm improvements after robot-aided therapy [34] and the other reported long-term progress [38].

The two studies that compared data from a robottrained group with a control group reported significant differences in predominantly short-term measures of motor control $[32,38]$. These differences favored robotaided therapy. No such trend was reported for functional abilities.

All studies reported that the effects of robot-aided therapy were training-specific: improvements occurred only in the trained shoulder and elbow, and no increase in motor control or functional abilities occurred in the wrist or hand. None of the studies reported adverse effects of robot-aided therapy.

\section{Data Analysis}

Five of the eight studies measured pre- and posttreatment upper-limb FM scores after forward-directed robotaided therapy. Of these five studies, one studied subacute [32] and four studied chronic [34-36,38] stroke patients. We performed a quantitative meta-analysis of the four studies that involved chronic stroke patients [34-36,38]. Data presentation was insufficient in two of these studies $[34,38]$ because the standard deviation (SD) of the change in FM scores was missing; this left two studies ( $n=$ total of 70 in the experimental groups) for estimation of a pooled mean difference in FM scores before and after robot-aided therapy [35-36]. A standard chi-square test for heterogeneity [41] showed nonsignificant systematic variation between these two studies $\left(\chi^{2}=0.683, p=\right.$ 0.43 ); therefore, we used the fixed-effect model to estimate the pooled mean difference in FM scores [42].

Change in FM score (i.e., difference between average pre- and posttreatment scores, including SD) and corresponding 95 percent CI for each study are presented in Table 2 and displayed graphically in the Figure. A summary of the results of the two studies with sufficient data showed that robot-aided therapy positively influenced FM scores: the pooled average FM score increased 3.7 points $(95 \% \mathrm{CI}=2.8-4.7)$. This indicates a statistically significant 6 percent increase in motor control after robot-aided therapy $(p<0.05)$. The methodological quality scores of all studies are also included in Table 2 and the Figure. Methodological quality and reported changes in FM scores did not appear to be related.

To include estimated results of the two studies with missing SD, we performed a sensitivity analysis [43]. We calculated the adjusted pooled mean difference and the corresponding 95 percent CI for several possible SD values (ranging from 1 to 10 for both incomplete studies). This analysis showed that the adjusted pooled mean difference could vary from 4.0 to 4.7 points and the corresponding 95 percent CI from 3.2 to 6.2 points. Thus, the influence of robot-aided therapy is still positive when these two studies are incorporated. Results of the metaanalysis of the four studies support findings the of qualitative analysis of the eight selected studies.

\section{DISCUSSION}

In this systematic review, we qualitatively analyzed eight studies to assess the effect of robot-aided therapy on improvement of upper-limb motor control and functional abilities in stroke patients. The results of the analysis show that forward-directed robot-aided therapy improves several motor-control aspects (e.g., muscle activation patterns, selectivity, and speed of movement) and has longterm effects of several months to several years, as measured at follow-up. The additional quantitative data analysis of short-term changes in upper-limb FM scores supported the positive influence of robot-aided therapy on motor recovery in chronic stroke patients (the pooled mean FM scores after robot-aided therapy increased by $6 \%$ ). Reinkensmeyer et al. presented comparable findings in a narrative overview of published research [44], including some earlier MIT-Manus studies. In contrast, the Krebs et al. study that assessed vertical-movement training showed no significant change in motor control, although the results showed a distinct positive trend [37]. No consistent influence of robot-aided therapy on improvement of functional abilities could be detected from the qualitative analysis. This inconclusive finding is consistent with the minimal effect of interventions such as Bobath, neurodevelopmental therapy, proprioceptive neuromuscular facilitation, and Brunnstrom on ADL performance after stroke rehabilitation [45].

In studies with a robot-trained group and a control group, robot-aided therapy caused more short-term reduction 
in motor impairments, such as muscle activation patterns and selectivity and speed of movement, than conventional rehabilitation techniques. For functional abilities, no difference was found between the robot-trained and control groups. Only one study examined long-term effects so no firm conclusion can be drawn.

Research in this field is relatively young and few large RCTs have been conducted. Therefore, the factors that might affect the outcome of robot-aided therapy and bias current research findings are still unclear.
An obvious factor affecting the conclusions is that we included studies with both subacute and chronic stroke patients. No apparent difference in the positive influence of robot-aided therapy was found between these patient groups when we looked at all outcome measures qualitatively, but the number of included studies (one subacute, seven chronic) is too small for us to draw firm conclusions. Nevertheless, this information indicates that both subacute and chronic stroke patients can improve upper-

Table 1.

Characteristics of selected studies on robot-aided therapy in stroke rehabilitation.

\begin{tabular}{|c|c|c|c|c|c|c|}
\hline Study & Robotic Principle & $N$ & Diagnosis & $\begin{array}{c}\text { Age } \\
(\text { Mean } \pm \text { SD) }\end{array}$ & $\begin{array}{l}\text { Time Poststroke } \\
\text { (Mean } \pm \text { SD) }\end{array}$ & Intervention \\
\hline [1] & $\begin{array}{l}\text { MIT-Manus; passive, active- } \\
\text { assisted + active-resisted move- } \\
\text { ment }\end{array}$ & $\begin{array}{l}\text { E: } 40 \\
\text { C: } 36\end{array}$ & Subacute & $\begin{array}{l}\text { E: } 61.1 \pm 4.4^{*} \\
\text { C: } 65.9 \pm 5.7^{*}\end{array}$ & $\begin{array}{l}\mathrm{E}: 2.2 \pm 0.3 \mathrm{wk}^{*} \\
\mathrm{C}: 2.6 \pm 0.7 \mathrm{wk}^{*}\end{array}$ & $\begin{array}{l}\text { E: Conventional + robot therapy } 4-5 \mathrm{~h} / \mathrm{wk} \text { for } 6 \mathrm{wk} \\
\text { C: Conventional + robot exposure } 1 \mathrm{~h} / \mathrm{wk} \text { for } 6 \mathrm{wk}\end{array}$ \\
\hline [2] & $\begin{array}{l}\text { MIT-Manus; passive, active- } \\
\text { assisted + active-resisted } \\
\text { movement }\end{array}$ & E: 30 & Chronic & E: $64.8 \pm 2.3$ & $\begin{array}{l}\mathrm{E}: 1,299 \pm 147 \mathrm{~d} \\
(\sim 43 \mathrm{mo})\end{array}$ & Robot therapy $3 \mathrm{~h} / \mathrm{wk}$ for $6 \mathrm{wk}$ \\
\hline [3] & $\begin{array}{l}\text { InMotion }^{2} \text { (previous MIT- } \\
\text { Manus); active-assisted + } \\
\text { active-resisted movement }\end{array}$ & E: 42 & Chronic & E: $57.4 \pm 13.9$ & $\mathrm{E}: 28.7 \pm 12.4 \mathrm{mo}$ & Robot therapy $3 \mathrm{~h} / \mathrm{wk}$ for $6 \mathrm{wk}$ \\
\hline [4] & $\begin{array}{l}\text { InMotion }^{2} \text { (previous MIT- } \\
\text { Manus); active-assisted or } \\
\text { active-resisted movement }\end{array}$ & $\mathrm{E}: 46^{\dagger}$ & Chronic & E: $57.6 \pm 13.6$ & $\mathrm{E}: 26.1 \pm 12.4 \mathrm{mo}$ & Robot therapy $3 \mathrm{~h} / \mathrm{wk}$ for $6 \mathrm{wk}$ (assisted or resisted) \\
\hline [5] & $\begin{array}{l}\text { MIT-Manus; passive, active- } \\
\text { assisted + active-resisted } \\
\text { movement }\end{array}$ & E: 9 & Chronic & E: $62.0 \pm 4.3$ & $\mathrm{E}: 50.0 \pm 8.9 \mathrm{mo}$ & $\begin{array}{l}\text { Robot therapy in horizontal plane } 3 \mathrm{~h} / \mathrm{wk} \text { for } 6 \mathrm{wk} \\
\& \text { in vertical plane } 3 \mathrm{~h} / \mathrm{wk} \text { for } 6 \mathrm{wk}\end{array}$ \\
\hline [6] & $\begin{array}{l}\text { MIME; passive, active-assisted } \\
\text { + active-resisted movement }\end{array}$ & $\begin{array}{l}\mathrm{E}: 13 \\
\mathrm{C}: 14\end{array}$ & Chronic & $\begin{array}{l}\text { E: } 63.2 \pm 3.6 \\
\text { C: } 65.9 \pm 2.4\end{array}$ & $\begin{array}{l}\mathrm{E}: 30.2 \pm 6.2 \mathrm{mo} \\
\mathrm{C}: 28.8 \pm 6.3 \mathrm{mo}\end{array}$ & $\begin{array}{l}\text { E: Robot therapy } 3 \mathrm{~h} / \mathrm{wk} \text { for } 8 \mathrm{wk} \\
\mathrm{C} \text { : Conventional } 3 \mathrm{~h} / \mathrm{wk} \text { for } 8 \mathrm{wk}+ \\
\text { noncontact robot exposure }\end{array}$ \\
\hline [7] & $\begin{array}{l}\text { MIME; passive, active-assisted } \\
\text { + active-resisted movement }\end{array}$ & E: 13 & Chronic & E: $63.2 \pm 12.8$ & $\mathrm{E}: 30.2 \pm 22.2 \mathrm{mo}$ & Robot therapy $3 \mathrm{~h} / \mathrm{wk}$ for $8 \mathrm{wk}$ \\
\hline [8] & $\begin{array}{l}\text { ARM Guide; passive + active- } \\
\text { assisted movement }\end{array}$ & $\mathrm{E}: 3$ & Chronic & E: $41.0 \pm 9.6$ & $\mathrm{E}: 4.3 \pm 1.7 \mathrm{yr}$ & $\begin{array}{l}\text { Robot therapy } 3 \mathrm{~h} / \mathrm{wk} \text { for } 8 \mathrm{wk}(n=2) \text { or } 4 \mathrm{wk} \\
(n=1)\end{array}$ \\
\hline \multicolumn{7}{|c|}{$\begin{array}{l}\text { 1. Krebs HI, Volpe BT, Aisen ML, Hogan N. Increasing productivity and quality of care: Robot-aided neuro-rehabilitation. J Rehabil Res Dev. 2000;37(6):639-52 } \\
\text { 2. Ferraro M, Palazzolo JJ, Krol J, Krebs HI, Hogan N, Volpe BT. Robot-aided sensorimotor arm training improves outcome in patients with chronic stroke. } \\
\text { 3. Fasoli SE, Krebs HI, Stein J, Frontera WR, Hughes R, Hogan N. Robotic therapy for chronic motor impairments after stroke: follow-up results. Arch Phys Med } \\
\text { 4. Stein J, Krebs HI, Frontera WR, Fasoli SE, Hughes R, Hogan N. Comparison of two techniques of robot-aided upper limb exercise training after stroke. Am J } \\
\text { 5. Krebs HI, Ferraro M, Buerger SP, Newbery MJ, Makiyama A, Sandmann M, Lynch D, Volpe BT, Hogan N. Rehabilitation robotics: pilot trial of a spatial extension } \\
\text { 6. Lum PS, Burgar CG, Shor PC, Majmundar M, Van der Loos M. Robot-assisted movement training compared with conventional therapy techniques for the rehabilitation } \\
\text { 7. Lum PS, Burgar CG, Shor PC. Evidence for improved muscle activation patterns after retraining of reaching movements with the MIME robotic system in subjects } \\
\text { 8. Reinkensmeyer DJ, Kahn LE, Averbuch M, McKenn-Cole A, Schmit BD, Rymer WZ. Understanding and treating arm movement impairment after chronic brain } \\
\text { ARM = Assisted Rehabilitation and Measurement (guide), AROM = active range of motion; AS = Ashworth Scale (spasticity); BI = Barthel Index (activities of } \\
\text { FM = Fugl-Meyer (motor recovery); kinematics = movement execution related to position, speed, etc.; MIME = Mirror Image Motion Enabler; MIT = Massachusetts } \\
\text { (isometric muscle strength); pain = experienced intensity of pain; ROM = range of motion (maximal movement or reach); s/e = shoulder and elbow; tone = muscle tone } \\
\text { Data from two separate but related studies since this information was not in current article [1]; we averaged mean and pooled variance over all participants. } \\
{ }^{\dagger} 18 \text { subjects had very severe impairments and could not participate in randomization; thus } n=28 \text { subjects were randomized across groups and analyzed. }\end{array}$} \\
\hline
\end{tabular}


limb function after robot-aided therapy. Although this result seems to contradict the traditional assumption that most recovery occurs within the first 3 to 6 mo after stroke with no further improvements later on [46-47], it is consistent with several more recent publications that claim that chronic patients (i.e., more than 6 mo poststroke) can improve upper-limb function [1,48-49]. The pooled mean increase in chronic stroke patients' FM scores after robot-aided therapy support the results of these recent studies.
A second potential bias is the difference in treatment intensity between experimental and control groups. In Krebs et al.’s summary study [32], the robot-trained group received more hours of therapy (robot-aided therapy plus conventional therapy) than the control group (conventional therapy alone). This difference may have overestimated the effect of robot-aided therapy, since higher intensity therapy has been reported to lead to better results than lower intensity therapy [6,50-51].

Table 1. (Continued from across left page)

Characteristics of selected studies on robot-aided therapy in stroke rehabilitation.

\begin{tabular}{|c|c|c|c|c|}
\hline \multirow{2}{*}{$\begin{array}{l}\text { Follow- } \\
\text { Up }\end{array}$} & \multicolumn{2}{|c|}{ Outcome Measures } & \multirow{2}{*}{ Conclusions } & \multirow{2}{*}{$\begin{array}{l}\text { Methodological } \\
\text { Quality Score }\end{array}$} \\
\hline & Motor Control & Functional Ability & & \\
\hline $\begin{array}{c}3 \mathrm{yr} \\
(n=6)\end{array}$ & $\begin{array}{l}\text { FM, MSS (s/e), MSS (w/h), } \\
\text { MP, kinematics (individual data) }\end{array}$ & - & $\begin{array}{l}\text { Robot training improved all parameters. } \\
\text { Improvement larger for MSS (s/e) \& MP vs control. } \\
\text { Long-term only for MSS (s/e). }\end{array}$ & 12 \\
\hline $3 \mathrm{mo}$ & $\begin{array}{l}\text { FM, MSS (s/e), MSS (w/h), } \\
\text { MP, AS }\end{array}$ & - & $\begin{array}{l}\text { Robot training improved FM \& MP (sustained at follow-up). } \\
\text { Improvements favored moderate stroke; FIM improvement for } \\
\text { moderately severe stroke patients only. }\end{array}$ & 14 \\
\hline $\begin{array}{c}4 \text { mo } \\
(n=40)\end{array}$ & $\begin{array}{l}\text { FM, MSS (s/e), MSS (w/h), } \\
\text { MP, AS, MVC }\end{array}$ & FIM & $\begin{array}{l}\text { Robot training improved FM, s/e MSS \& MP (sustained at } \\
\text { follow-up). Reduced short- \& long-term shoulder pain. } \\
\text { Effects training-specific. }\end{array}$ & 15 \\
\hline- & $\begin{array}{l}\text { FM, MSS (s/e), MSS (w/h), } \\
\text { MP, AS, pain }\end{array}$ & - & $\begin{array}{l}\text { Robot training improved FM, s/e MSS, \& MVC. } \\
\text { No significant difference between assisted \& resisted robot training. }\end{array}$ & 16 \\
\hline- & FM, MSS (s/e), MP, AS & - & $\begin{array}{l}\text { Reduced impairment after robot training in vertical plane was } \\
\text { not significant for s/e FM, MSS, MP, \& AS but comparable } \\
\text { with improvement after planar robot training. No information } \\
\text { about w/h. }\end{array}$ & 11 \\
\hline $6 \mathrm{mo}$ & FM, MVC, kinematics & BI, FIM & $\begin{array}{l}\text { Robot training improved all motor control measures (short- \& } \\
\text { long-term) but only long-term for functional abilities. Robot group } \\
\text { improved control in motor control (short-term) \& in functional } \\
\text { abilities (long-term) for all measures. }\end{array}$ & 16 \\
\hline- & $\begin{array}{l}\text { EMG, strength, active ROM, } \\
\text { kinematics }\end{array}$ & - & $\begin{array}{l}\text { Robot training significantly improved kinematics \& EMG } \\
\text { (reach at shoulder level but not elbow height). }\end{array}$ & 10 \\
\hline- & $\begin{array}{l}\text { Active ROM, tone, kinetics + } \\
\text { kinematics }\end{array}$ & - & $\begin{array}{l}\text { Robot training improved AROM, peak movement speed, \& tone; } \\
\text { results of incoordination \& free-reaching inconsistent. }\end{array}$ & 8 \\
\hline
\end{tabular}

Neurology. 2003;61(11):1604-7. [PMID: 14663051]

Rehabil. 2004;85(7):1106-11. [PMID: 15241758]

Phys Med Rehabil. 2004;83(9):720-28. [PMID: 15314537]

for MIT-Manus. J Neuroengineering Rehabil. 2004;1(1):5. [PMID: 15679916]

of upper-limb motor function after stroke. Arch Phys Med Rehabil. 2002;83(7):952-59. [PMID: 12098155]

with post-stroke hemiparesis. IEEE Trans Neural Syst Rehabil Eng. 2004;12(2):186-94. [PMID: 15218933]

injury: progress with the ARM guide. J Rehabil Res Dev. 2000;37(6):653-62. [PMID: 11321001]

daily living); C = control; E = experimental; EMG = electromyography (muscle activation); FIM = Functional Independence Measure (activities of daily living); Institute of Technology, MP = Motor Power (isolated muscle strength); MSS = Motor Status Scale (motor function); MVC = Maximal Voluntary Contraction (stiffness of muscles), $\mathrm{w} / \mathrm{h}=$ wrist and hand. 
JRRD, Volume 43, Number 2, 2006

Table 2.

Change in Fugl-Meyer (FM) scores (upper-limb portion only) after robot-aided therapy in chronic stroke patients.

\begin{tabular}{lcccc}
\multicolumn{1}{c}{ Study } & Methodological Quality Score & $\boldsymbol{N}$ & Change in FM (Mean \pm SD) & 95\% CI \\
\hline Ferraro 2003 [1] & 14 & 28 & 6.1 & - \\
Fasoli 2004 [2] & 15 & 42 & $3.4 \pm 4.0$ & $2.2-4.6$ \\
Stein 2004 [3] & 16 & 28 & $4.2 \pm 4.2$ & $2.6-5.8$ \\
Lum 2002 [4] $^{*}$ & 16 & 13 & 4.7 & - \\
Pooled Average $^{\ddagger}$ & - & 70 & $3.7 \pm 0.5$ & $2.8-4.7$
\end{tabular}

1. Ferraro M, Palazzolo JJ, Krol J, Krebs HI, Hogan N, Volpe BT. Robot-aided sensorimotor arm training improves outcome in patients with chronic stroke. Neurology. 2003;61(11):1604-7. [PMID: 14663051]

2. Fasoli SE, Krebs HI, Stein J, Frontera WR, Hughes R, Hogan N. Robotic therapy for chronic motor impairments after stroke: follow-up results. Arch Phys Med Rehabil. 2004;85(7):1106-11. [PMID: 15241758]

3. Stein J, Krebs HI, Frontera WR, Fasoli SE, Hughes R, Hogan N. Comparison of two techniques of robot-aided upper limb exercise training after stroke. Am J Phys Med Rehabil. 2004;83(9):720-28. [PMID: 15314537]

4. Lum PS, Burgar CG, Shor PC, Majmundar M, Van der Loos M. Robot-assisted movement training compared with conventional therapy techniques for the rehabilitation of upper-limb motor function after stroke. Arch Phys Med Rehabil. 2002;83(7):952-59. [PMID: 12098155]

*Cumulative mean change in shoulder/elbow and wrist/hand components of FM; study only presented pre- and posttreatment scores so SD could not be calculated.

${ }^{\dagger}$ Data pooling of four groups with two separate robot-training regimens (mean = average of the four groups, SD = pooled estimation of variance in the four groups).

${ }^{\ddagger}$ Pooled average difference in FM and total $N$ based on Fasoli 2004 [2] and Stein 2004 [3], the two studies with sufficient data (i.e., mean and SD of change in FM score).

$\mathrm{CI}=$ confidence interval, $\mathrm{SD}=$ standard deviation.

Nonetheless, the potential motor-control benefit of robotaided therapy over conventional therapy is supported by the positive findings of the other controlled trial, in which the robot-trained and control groups received equal treatment intensity [38].

A third possible bias is the use of the upper-limb portion of FM for quantitative analysis. Although the influence of robot-aided therapy was training-specific in all eight studies (i.e., only detectable in shoulder and elbow), only the score of the upper-limb portion of the FM was reported; therefore, this measure (which included assessment of wrist and hand recovery) was used for pooling data. Calculation of total scores for assessment of training-specific improvements in motor control might have underestimated the influence of robot-aided therapy on clinical outcome. This may explain, in part, why the 6 percent increase in the upper-limb FM score after robot-aided therapy was statistically significant but not clinically relevant ( $\geq 10 \%$ increase in FM score) [52]. Thus, robot-aided therapy may be even more beneficial for reduction of motor impairments than postulated by our results.

Despite these potential limitations, our results justify more in-depth study of the positive effects of robot-aided therapy and the factors that influence these effects.

One interesting aspect concerns the different response to robot-aided therapy by different patient groups. Ferraro et al. distinguished between moderately and severely affected stroke patients (based on Canadian Neurological Scale and National Institutes of Health
Stroke Scale stroke-severity estimates) and reported that moderately affected patients were more responsive to robot-aided therapy than severely affected patients [34]. This finding is consistent with other authors' findings that high initial motor function likely promotes positive stroke-rehabilitation outcome in general [1,46-47,53]. Another study in our review reported similar results: the patients with the highest initial motor function increased more on motor-control measures after robot-aided therapy than the patients with the lowest initial motor function [36]. Accordingly, inclusion of subgroup analyses based on stroke severity in future studies would more extensively assess motor-outcome differences after robotaided therapy and expand our knowledge of the patient groups that benefit most from robot-aided therapy.

A second interesting aspect of our review concerns training specificity. In the studies we analyzed, only the shoulder and elbow were trained and only motor control of the shoulder and elbow improved. However, proper wrist and hand use is particularly relevant for functional use of the hemiparetic arm. The focus on the shoulder and elbow in these studies may partially explain the lack of functional ability improvement after robot-aided therapy. So, future attention on the wrist and hand may maximize the gains from robot-aided therapy. Research groups have recognized the importance of studying the wrist and hand and are extending their robot devices with distal trainers [54]. One group developed a separate robot device for distal upper-limb training and performed two 


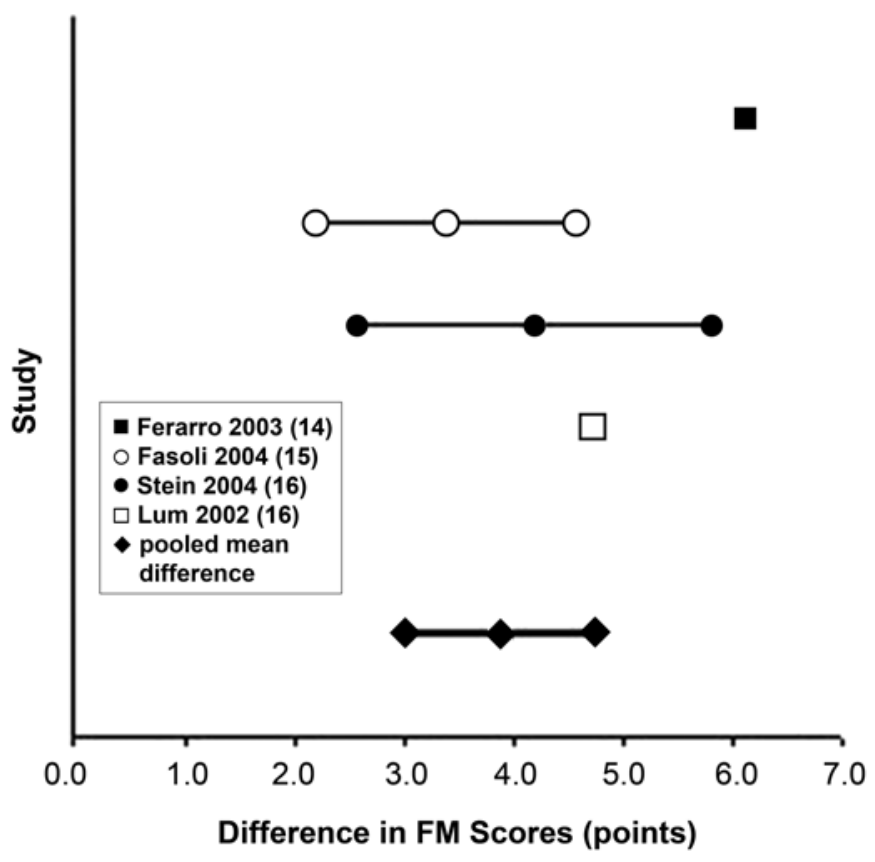

Figure.

Difference in Fugl-Meyer (FM) scores (upper-limb portion only) after robot-aided therapy with chronic stroke patients. Mean change from pre- to posttreatment (middle symbol on each line) and corresponding 95\% confidence interval (CI) (outer symbols on each line) shown for each study. Ferraro 2003 and Lum 2002 were missing standard deviation values; therefore, only mean change shown. Methodological quality score for each study shown in parenthesis in legend (maximum possible score $=19$ ). Line with solid diamonds is pooled mean change in FM score (middle symbol) and 95\% CI (outer symbols) for Fasoli 2004 and Stein 2004, the studies with complete data. Sources: Ferraro M, Palazzolo JJ, Krol J, Krebs HI, Hogan N, Volpe BT. Robot-aided sensorimotor arm training improves outcome in patients with chronic stroke. Neurology. 2003;61(11):1604-7 [PMID: 14663051]. Fasoli SE, Krebs HI, Stein J, Frontera WR, Hughes R, Hogan N. Robotic therapy for chronic motor impairments after stroke: follow-up results. Arch Phys Med Rehabil. 2004;85(7):1106-11 [PMID: 15241758]. Stein J, Krebs HI, Frontera WR, Fasoli SE, Hughes R, Hogan N. Comparison of two techniques of robot-aided upper limb exercise training after stroke. Am J Phys Med Rehabil. 2004;83(9):720-28 [PMID: 15314537]. Lum PS, Burgar CG, Shor PC, Majmundar M, Van der Loos M. Robot-assisted movement training compared with conventional therapy techniques for the rehabilitation of upper-limb motor function after stroke. Arch Phys Med Rehabil. 2002;83(7):952-59 [PMID: 12098155].

clinical studies with encouraging results on enhanced recovery of pronation-supination and wrist flexion-extension with the Bi-Manu-Track device [12,40].

A third interesting but unclear aspect is the role of individual treatment modalities in robot-aided therapy. Most trials implemented three different modalities in one robotic treatment protocol: passive, active-assisted, and active-resisted movements. However, these modalities were generally not tested separately; only the overall effect of robot-aided therapy was evaluated. One treatment modality may be much more effective than another. Only Fasoli et al. [33] and Stein et al. [36] tried to specify the separate contributions of treatment modalities. Fasoli et al.'s results suggest that robot-aided therapy that incorporates active-resisted movements is more beneficial than active-assisted therapy for upper-limb recovery because a carryover effect on motor control in the untrained wrist and hand was found only after activeresisted therapy with the trained proximal arm [33]. However, in a replication study by the same research group, a larger sample of participants revealed no differences in motor recovery between active-assisted and active-resisted therapy, possibly because of differences in analytic methods [36]. The Fasoli et al. study included patients who did not have sufficient initial function to participate in the active-resisted training group and were "allocated" to the robot-assisted group instead [33], which was not the case in Stein et al. [36]. Consequently, results from the active-resisted training group were overestimated. These findings show that certain types of robot-aided therapy may be less appropriate for certain patient groups. However, the contribution of individual training modalities to restoration of upper-limb function remains ambiguous.

Other treatment modalities may be relevant and suitable for incorporation into robot-aided therapy but have not yet been extensively explored. One possible modality is compensation of gravity for the upper limb. Most robotic devices provide some arm support, a feature that Sanchez et al. outlined [55]. However, Beer et al. specifically researched the potential of compensation of gravity on the upper limb [55-58]. In previous research, they found that several muscle activation patterns are coupled in abnormal synergies during active torque generation in the hemiparetic upper limb (e.g., shoulder abduction by stroke patients impaired their ability to extend the elbow) [56-57]. In subsequent research, they demonstrated that stroke patients' motor performance improved instantaneously without the influence of gravity on the upper limb because of a diminished need for active shoulder abduction and consequently increased ability to extend the elbow in static conditions [58]. Recent preliminary results suggest that the same mechanisms apply to dynamic conditions [59]. These findings indicate that 
compensation of gravity may stimulate improved motor performance of the upper limb. However, in a trial of single-case series, a group that received training with sling suspension of the upper limb (to support the arm against gravity) showed no improvement with respect to baseline [13]. Compensation of gravity, while fairly unexplored, may further stimulate upper-limb recovery in stroke patients. More research on this topic may give insight into which mechanisms are influenced by gravity compensation and may identify potential applications.

In addition to robot-aided therapy, other treatment types may effectively stimulate recovery after stroke. For example, preliminary results of Kahn et al.'s pilot study suggested that a group that received robot-assisted reach training (target is always reached) and a group that attempted to reach independently (no obligation to reach the target) had similar improvements in motor control [60]. Other approaches to stroke rehabilitation that have shown promising results include functional electrical stimulation [61], pharmacology [62], and several exercise therapy approaches [50], including repetitive exercise [60]; constraint induced therapy [63], including a recently developed automated application [64-65]; and sensorimotor training [5]. However, overall comparisons of the effectiveness of several treatments are not abundant, and the available overviews are not conclusive as to the best approach for assisting recovery after stroke [4,66-67]. Future research should shed more light on the effectiveness of these interventions compared with or even in combination with one another.

\section{CONCLUSIONS}

This systematic review indicates that robot-aided therapy of the proximal upper limb can improve shortand long-term motor control of the paretic shoulder and elbow. This conclusion is supported by a quantitative analysis of short-term pooled FM data in chronic stroke patients and indicates that increased motor recovery of chronic patients is possible after robot-aided therapy. However, no consistent effect on the improvement in functional abilities has been reported. Restoration of motor control appears greater after robot-aided therapy than conventional therapy. We could not establish which aspects of robot-aided therapy (e.g., increased intensity of movements, most effective training modalities) were most responsible for the beneficial influence on recovery.
The clinical relevance of our findings is that robotaided therapy is a promising new approach to rehabilitation of upper-limb motor control after stroke. For both subacute and chronic stroke patients, robot-aided therapy can improve motor control of the hemiparetic upper limb, perhaps even more than conventional therapy.

\section{ACKNOWLEDGMENTS}

This material was the result of work supported by SenterNovem, the Netherlands, grant TSGE2050.

The authors have declared that no competing interests exist.

\section{REFERENCES}

1. Broeks JG, Lankhorst GJ, Rumping K, Prevo AJ. The longterm outcome of arm function after stroke: results of a follow-up study. Disabil Rehabil. 1999;21(8):357-64. [PMID: 10503976]

2. Ingall T. Stroke-Incidence, mortality, morbidity and risk. J Insur Med. 2004;36(2):143-52. [PMID: 15301227]

3. Limburg M, Hijdra A, Cools HJM. Cerebrovascular disease [Dutch]. Houten (the Netherlands): Bohn Stafleu Van Loghum; 2000.

4. Barreca S, Wolf SL, Fasoli S, Bohannon R. Treatment interventions for the paretic upper limb of stroke survivors: a critical review. Neurorehabil Neural Repair. 2003;17(4): 220-26. [PMID: 14677218$]$

5. Feys HM, De Weerdt WJ, Selz BE, Cox Steck GA, Spichiger R, Vereeck CE, Putman KD, Van Hoydonck GA. Effect of a therapeutic intervention for the hemiplegic upper limb in the acute phase after stroke. A single-blind, randomized, controlled multicenter trial. Stroke. 1998; 29(4):785-92. [PMID: 9550512]

6. Kwakkel G, Wagenaar RC, Twisk JW, Lankhorst GJ, Koetsier JC. Intensity of leg and arm training after primary middle-cerebral-artery stroke: a randomized trial. Lancet. 1999;354(9174):191-96. [PMID: 10421300$]$

7. Volpe BT, Ferraro M, Krebs HI, Hogan N. Robotics in the rehabilitation treatment of patients with stroke. Curr Atheroscler Rep. 2002;4(4):270-76. [PMID: 12052277]

8. Lum P, Reinkensmeyer DJ, Mahoney R, Rymer WZ, Burgar C. Robotic devices for movement therapy after stroke: current status and challenges to clinical acceptance. Top Stroke Rehabil. 2002;8(4):40-53. [PMID: 14523729]

9. Krebs HI, Hogan N, Volpe BT, Aisen ML, Edelstein L, Diels C. Overview of clinical trials with MIT-MANUS: a 
robot-aided neuro-rehabilitation facility. Technol Health Care. 1999;7(6):419-23. [PMID: 10665675]

10. Reinkensmeyer DJ, Kahn LE, Averbuch M, McKennaCole A, Schmit BD, Rymer WZ. Understanding and treating arm movement impairment after chronic brain injury: progress with the ARM guide. J Rehabil Res Dev. 2000; 37(6):653-62. [PMID: 11321001]

11. Burgar CG, Lum PS, Shor PC, Machiel Van der Loos HF. Development of robots for rehabilitation therapy: the Palo Alto VA/Stanford experience. J Rehabil Res Dev. 2000; 37(6):663-73. [PMID: 11321002]

12. Hesse S, Schulte-Tigges G, Konrad M, Bardeleben A, Werner C. Robot-assisted arm trainer for the passive and active practice of bilateral forearm and wrist movements in hemiparetic subjects. Arch Phys Med Rehabil. 2003;84(6): 915-20. [PMID: 12808550]

13. Coote S, Stokes E, Murphy B, Harwin W. The effect of GENTLE/s robot-mediated therapy on upper extremity dysfunction post stroke. In: Proceedings of the 8th International Conference on Rehabilitation Robotics; 2003 Apr 23-25; Daejeon, Korea. Daejeon (Korea): Human-Friendly Welfare Robot System Engineering Research Center; 2003. p. 59-61.

14. Fanin C, Gallina P, Rossi A, Zanatta U, Masiero S. NeReBot: a wire-based robot for neurorehabilitation. In: Proceedings of the 8th International Conference on Rehabilitation Robotics; 2003 Apr 23-25; Daejeon, Korea. Daejeon (Korea): Human-Friendly Welfare Robot System Engineering Research Center; 2003. p. 23-26.

15. Toth A, Fazekas G, Arz G, Jurak M, Horvath M. Passive robotic movement therapy of the spastic hemiparetic arm with REHAROB: report of the first clinical test and the follow-up system improvement. In: Proceedings of the 9th International Conference on Rehabilitation Robotics; 2005 Jun 28-Jul 1; Chicago, Illinois. Madison (WI): Omnipress; 2005. p. 127-30.

16. Dewald J, Ellis MD, Holubar BG, Sukal T, Acosta AM. The robot application in the rehabilitation of stroke patients [Abstract]. Neurol Rehabil. 2004;(4):S7.

17. Nef T, Riener R. ARMin-Design of a novel arm rehabilitation robot. In: Proceedings of the 9th International Conference on Rehabilitation Robotics; 2005 Jun 28-Jul 1; Chicago, Illinois. Madison (WI): Omnipress; 2005. p. 57-60.

18. Arz G, Toth A, Fazekas G, Bratanov D, Zlatov N. Threedimensional anti-spastic physiotherapy with the industrial robots of "REHAROB.” In: Proceedings of the 8th International Conference on Rehabilitation Robotics; 2003 Apr 23-25; Daejeon, Korea. Daejeon (Korea): Human-Friendly Welfare Robot System Engineering Research Center; 2003. p. 215-18.

19. Riener R, Frey M, Nef T, Bernhardt M, Colombo G. New developments in rehabilitation robotics. In: IEEE Mecha- tronics and Robotics Conference; 2004 Sep 13-15; Aachen, Germany. Aachen (Germany): Sascha Eysoldt Verlag; 2004. p. 1397-1402.

20. Charles SK, Krebs HI, Volpe BT, Lynch D, Hogan N. Wrist rehabilitation following stroke: initial clinical results. In: Proceedings of the 9th International Conference on Rehabilitation Robotics; 2005 Jun 28-Jul 1; Chicago, Illinois. Madison (WI): Omnipress; 2005. p. 13-16.

21. Furusho J, Koyanagi K, Imada Y, Fujii Y, Nakanishi K, Domen K, Miyakoshi K, Ryu U, Takenaka S, Inoue A. A 3-D rehabilitation system for upper limbs developed in a 5-year NEDO project and its clinical testing. In: Proceedings of the 9th International Conference on Rehabilitation Robotics; 2005 Jun 28-Jul 1; Chicago, Illinois. Madison (WI): Omnipress; 2005. p. 53-56.

22. Colombo R, Pisano F, Micera S, Mazzone A, Delconte C, Carrozza MC, Dario P, Minuco G. Upper limb rehabilitation and evaluation of stroke patients using robot-aided techniques. In: Proceedings of the 9th International Conference on Rehabilitation Robotics; 2005 Jun 28-Jul 1; Chicago, Illinois. Madison (WI): Omnipress; 2005. p. 515-18.

23. Merians AS, Jack D, Boian R, Tremaine M, Burdea GC, Adamovich SV, Recce M, Poizner H. Virtual reality-augmented rehabilitation for patients following stroke. Phys Ther. 2002;82(9):898-915. [PMID: 12201804]

24. Kline T, Kamper D, Schmit B. Control system for pneumatically controlled glove to assist in grasp activities. In: Proceedings of the 9th International Conference on Rehabilitation Robotics; 2005 Jun 28-Jul 1; Chicago, Illinois. Madison (WI): Omnipress; 2005. p. 78-81.

25. Mulas M, Folgheraiter M, Gini G. An EMG-controlled exoskeleton for hand rehabilitation. In: Proceedings of the 9th International Conference on Rehabilitation Robotics; 2005 Jun 28-Jul 1; Chicago, Illinois. Madison (WI): Omnipress; 2005. p. 371-74.

26. Kottink AI, Oostendorp LJ, Buurke JH, Nene AV, Hermens HJ, IJzerman MJ. The orthotic effect of functional electrical stimulation on the improvement of walking in stroke patients with a dropped foot: a systematic review. Artif Organs. 2004;28(6):577-86. [PMID: 15153151]

27. Van Tulder MW, Assendelft WJ, Koes BW, Bouter LM. Method guidelines for systematic reviews in the Cochrane Collaboration Back Review Group for Spinal Disorders. Spine. 1997;22(20):2323-30. [PMID: 9355211]

28. Aisen ML, Krebs HI, Hogan N, McDowell F, Volpe BT. The effect of robot-assisted therapy and rehabilitative training on motor recovery following stroke. Arch Neurol. 1997;54(4):443-46. [PMID: 9109746]

29. Krebs HI, Hogan N, Aisen ML, Volpe BT. Robot-aided neurorehabilitation. IEEE Trans Rehabil Eng. 1998;6(1): 75-87. [PMID: 9535526] 
30. Volpe BT, Krebs HI, Hogan N, Edelsteinn L, Diels CM, Aisen ML. Robot training enhanced motor outcome in patients with stroke maintained over 3 years. Neurology. 1999;53(8):1874-76. [PMID: 10563646]

31. Volpe BT, Krebs HI, Hogan N, Edelstein OTR L, Diels C, Aisen M. A novel approach to stroke rehabilitation: robotaided sensorimotor stimulation. Neurology. 2000;54(10): 1938-44. [PMID: 10822433]

32. Krebs HI, Volpe BT, Aisen ML, Hogan N. Increasing productivity and quality of care: Robot-aided neuro-rehabilitation. J Rehabil Res Dev. 2000;37(6):639-52.

[PMID: 11321000]

33. Fasoli SE, Krebs HI, Stein J, Frontera WR, Hogan N. Effects of robotic therapy on motor impairment and recovery in chronic stroke. Arch Phys Med Rehabil. 2003; 84(4):477-82. [PMID: 12690583]

34. Ferraro M, Palazzolo JJ, Krol J, Krebs HI, Hogan N, Volpe BT. Robot-aided sensorimotor arm training improves outcome in patients with chronic stroke. Neurology. 2003; 61(11):1604-7. [PMID: 14663051]

35. Fasoli SE, Krebs HI, Stein J, Frontera WR, Hughes R, Hogan N. Robotic therapy for chronic motor impairments after stroke: follow-up results. Arch Phys Med Rehabil. 2004;85(7):1106-11. [PMID: 15241758]

36. Stein J, Krebs HI, Frontera WR, Fasoli SE, Hughes R, Hogan N. Comparison of two techniques of robot-aided upper limb exercise training after stroke. Am J Phys Med Rehabil. 2004;83(9):720-28. [PMID: 15314537]

37. Krebs HI, Ferraro M, Buerger SP, Newbery MJ, Makiyama A, Sandmann M, Lynch D, Volpe BT, Hogan N. Rehabilitation robotics: pilot trial of a spatial extension for MITManus. J Neuroengineering Rehabil. 2004;1(1):5.

[PMID: 15679916]

38. Lum PS, Burgar CG, Shor PC, Majmundar M, Van der Loos M. Robot-assisted movement training compared with conventional therapy techniques for the rehabilitation of upper-limb motor function after stroke. Arch Phys Med Rehabil. 2002;83(7):952-59. [PMID: 12098155]

39. Lum PS, Burgar CG, Shor PC. Evidence for improved muscle activation patterns after retraining of reaching movements with the MIME robotic system in subjects with poststroke hemiparesis. IEEE Trans Neural Syst Rehabil Eng. 2004;12(2):186-94. [PMID: 15218933]

40. Hesse S, Werner C, Pohl M, Rueckriem S, Mehrholz J, Lingnau ML. Computerized arm training improves the motor control of the severely affected arm after stroke: a singe-blinded randomized trial in two centers. Stroke. 2005;36(9):1960-66. [PMID: 16109908]

41. Sutton AJ, Abrams KR, Jones DR, Sheldon TA, Song F. Methods for meta-analysis in medical research. Chichester (England): John Wiley \& Sons; 2000. p. 37-56.
42. Sutton AJ, Abrams KR, Jones DR, Sheldon TA, Song F. Methods for meta-analysis in medical research. Chichester (England): John Wiley \& Sons; 2000. p. 57-72.

43. Abrams KR, Lambert PC, Sansó B, Shaw C. Meta-analysis of heterogeneously reported study results: a Bayesian approach. In: Stangl DK, Berry DA, editors. Meta-analysis in medicine and health policy. New York (NY): CRC; 2000. p. 29-63.

44. Reinkensmeyer DJ, Emken JL, Cramer SC. Robotics, motor learning, and neurologic recovery. Annu Rev Biomed Eng. 2004;6:497-525. [PMID: 15255778]

45. Wagenaar RC, Meijer OG. Effects of stroke rehabilitation. I: a critical review of the literature. J Rehabil Sci. 1991; 4(3):61-73, 97-109.

46. Jørgenson HS, Nakayama H, Raaschou HO, Vive-Larsen J, Støier M, Olsen TS. Outcome and time course of recovery in stroke. Part II: time course of recovery. The Copenhagen Stroke Study. Arch Phys Med Rehabil. 1995;76(5):406-12. [PMID: 7741609]

47. Hendricks HT, Van Limbeek J, Geurts AC, Zwarts MJ. Motor recovery after stroke: a systematic review of the literature. Arch Phys Med Rehabil. 2002;83(11):1629-37. [PMID: 12422337]

48. Cauraugh JH, Kim S. Two coupled motor recovery protocols are better than one: electromyogram-triggered neuromuscular stimulation and bilateral movements. Stroke. 2002;33(6):1589-94. [PMID: 12052996]

49. Page SJ, Gater DR, Bach-Y-Rita P. Reconsidering the motor recovery plateau in stroke rehabilitation. Arch Phys Med Rehabil. 2004;85(8):1377-81. [PMID: 15295770]

50. Van der Lee JH, Snels IA, Beckerman H, Lankhorst GJ, Wagenaar RC, Bouter LM. Exercise therapy for arm function in stroke patients: a systematic review of randomized controlled trials. Clin Rehabil. 2001;15(1):20-31. [PMID: 11237158]

51. Platz T. Evidence-based rehabilitation of the arm-A systematic review [German]. Nervenarzt. 2003;74(10): 841-49. [PMID: 14551687]

52. Gladstone DJ, Danells CJ, Black SE. The Fugl-Meyer assessment or motor recovery after stroke: a critical review of its measurement properties. Neurorehabil Neural Repair. 2002;16(3):232-40. [PMID: 12234086]

53. Reker DM, O’Donnell JC, Hamilton BB. Stroke rehabilitation outcome variation in Veterans Affairs rehabilitation units: accounting for case-mix. Arch Phys Med Rehabil. 1998;79(7):751-57. [PMID: 9685086]

54. Krebs HI, Celestino J, Williams D, Ferraro M, Volpe BT, Hogan N. A wrist extension to MIT-Manus. In: Bien Z, Stefanov D, editors. Advances in rehabilitation robotics: Human-friendly technologies on movement assistance and restoration for people with disabilities. Berlin-Heidelberg (Germany): Springer-Verlag; 2004. 
55. Sanchez RJ, Wolbrecht E, Smith R, Liu J, Rao S, Cramer S, Rahman T, Bobrow JE, Reinkensmeyer DJ. A pneumatic robot for re-training arm movement after stroke: rationale and mechanical design. In: Proceedings of the 9th International Conference on Rehabilitation Robotics; 2005 Jun 28-Jul 1; Chicago, Illinois. Madison (WI): Omnipress; 2005. p. 500-504.

56. Beer RF, Given JD, Dewald JP. Task-dependent weakness at the elbow in patients with hemiparesis. Arch Phys Med Rehabil. 1999;80(7):766-72. [PMID: 10414760]

57. Beer RF, Dewald JP, Rymer WZ. Deficits in the coordination of multijoint arm movements in patients with hemiparesis: evidence for disturbed control of limb dynamics. Exp Brain Res. 2000;131(3):305-19. [PMID: 10789946]

58. Beer RF, Dewald JP, Dawson ML, Rymer WZ. Targetdependent differences between free and constrained arm movements in chronic hemiparesis. Exp Brain Res. 2004; 156(4):458-70. [PMID: 14968276]

59. Sukal TM, Ellis MD, Dewald JPA. Dynamic characterization of upper limb discoordination following hemiparetic stroke. In: Proceedings of the 9th International Conference on Rehabilitation Robotics; 2005 Jun 28-Jul 1; Chicago, Illinois. Madison (WI): Omnipress; 2005. p. 519-21.

60. Kahn LE, Averbuch M, Rymer WZ, Reinkensmeyer DJ. Comparison of robot-assisted reaching to free reaching in promoting recovery from chronic stroke. In: Mokhtari M, editor. Integration of assistive technology in the information age. Amsterdam (the Netherlands): IOS Press; 2001. p. 39-44.

61. De Kroon JR, IJzerman MJ, Chae J, Lankhorst GJ, Zilvold G. Relation between stimulation characteristics and clinical outcome in studies using electrical stimulation to improve motor control of the upper extremity in stroke. J Rehabil Med. 2005;37(2):65-74. [PMID: 15788340]

62. Martinsson L, Wahlgren NG, Hardemark HG. Amphetamines for improving recovery after stroke. Cochrane Database Syst Rev. 2003;(3):CD002090.

[PMID: 12917919]

63. Wolf SL, Blanton S, Baer H, Breshears J, Butler AJ. Repetitive task practice: a critical review of constraint-induced movement therapy in stroke. Neurologist. 2002;8(6):325-38. [PMID: 12801434$]$

64. Lum PS, Taub E, Schwandt D, Postman M, Hardin P, Uswatte G. Automated Constraint-Induced Therapy Extension (AutoCITE) for movement deficits after stroke. J Rehabil Res Dev. 2004;41(3A):249-58.

[PMID: 15543442]

65. Taub E, Lum PS, Hardin P, Mark VW, Uswatte G. AutoCITE: Automated delivery of CI therapy with reduced effort by therapists. Stroke. 2005;36(6):1301-4. [PMID: 15879335]

66. Hesse S, Werner C. Poststroke motor dysfunction and spasticity: Novel pharmacological and physical treatment strategies. CNS Drugs. 2003;17(15):1093-1107. [PMID: 14661987]

67. Pomeroy VM, Tallis RC. Physical therapy to improve movement performance and functional ability poststroke. Part 1. Existing evidence. Clin Gerontol. 2000;10:261-90.

Submitted for publication April 27, 2005. Accepted in revised form September 30, 2005. 